\title{
AN EFFECTIVE PEDAGOGICAL PRACTISE FOR INTEGRATING HIV AND AIDS INTO TERTIARY EDUCATION: AN INTERIOR DESIGN CASE STUDY
}

\author{
A. Gill* \\ e-mail: agill@uj.ac.za \\ G. Di Monte-Milner* \\ e-mail: giovannadm@uj.ac.za \\ *Interior Design Department \\ University of Johannesburg \\ Johannesburg, South Africa
}

\section{ABSTRACT}

This article discusses a pedagogical practise used to introduce HIV and AIDS content into an existing Interior Design curriculum from a creative praxis perspective. Curriculum-integration is a key strategy of the Higher Education HIVIAIDS Programme (HEAIDS), which was established to develop and support HIV-mitigation programmes at South Africa's public Higher Education Institutions. Students within the Faculty of Art, Design and Architecture at the University of Johannesburg engaged in a spatial intervention project that was structured around project-based learning strategies and constructivist teaching values. Students' proposals were analysed against their ability to promote HIV and AIDS prevention and create appropriate meaning amongst the target group. The article suggests that the methodology proved effective because it did not require radical curriculum transformation; aligned with existing programme outcomes; and demonstrated potential to contribute to the 'new literacy of AIDS' required to counter 'AIDS fatigue'.

Keywords: curriculum-integration, Aids fatigue, Interior Design education, project-based learning, higher education institution, HIV and Aids.

\section{INTRODUCTION}

As the pandemic enters a third decade, there is evidence of an intellectual shift in the ways in which HIV and AIDS is being addressed. This has emerged from the understanding that 'the age group most affected by the pandemic regrettably feed into the workplace and institutions of higher education’ (Gobind and Ukpere 2014, 355; Shefer, Strebel and Jacobs 2012, 114). Because young people are most vulnerable to HIV and AIDS in South Africa (Mitchell and Smith 2003, 513), awareness and prevention programmes should be on-going tasks (Gobind and Ukpere 2012, 1). Creating more awareness of the pandemic can assist in decreasing HIV 
infections within universities (Gobind and Ukpere 2014, 353). There is a need to promote an emerging 'new literacy of AIDS' (Mitchell and Smith 2003, 518) to which Interior Design can contribute. The South African Department of Higher Education and Training (DHET) has responded to these issues through the implementation of the Higher Education HIV/AIDS Programme (HEAIDS), which aims to facilitate capacity-building through a curriculumintegration strategy (HEAIDS 2014).

The various arts-based disciplines within the Faculty of Art, Design and Architecture (FADA) at the University of Johannesburg (UJ) have actively participated in this curriculumintegration initiative since its inception in 2009. The Interior Design department now regularly includes a spatial intervention student project, where students are simultaneously educated about HIV and AIDS and discipline-specific content. This is undertaken using a project-based teaching and learning strategy. For 'effective teaching' of HIV and AIDS, learning should be participatory, experiential, dialogic, non-didactic, and should allow students to become knowledge producers (De Lange 2014, 380-381). The pedagogical practise discussed in this article represents an example of how HIV and AIDS content can be integrated into curricula without the need for radical curricular reform, a factor that may contribute to negative perceptions and 'faculty resistance to integration of HIV and AIDS' (Wood 2011, 825). This article reflects on the pedagogical practises and outcomes of the integrated project by using the methodology of creative praxis. Creative praxis is used to 'critically reflect upon creative practice as research’ (Grierson and Brearley 2009, 4).

In this article, we firstly present a discussion of current HIV and AIDS-related issues, followed by the response of higher education in South Africa. Thereafter, we describe the pedagogical practise used to support curriculum-integration; the use of project-based learning (PBL) and the implementation of the student project. The section thereafter describes the specific spatial design concepts that informed the student project, followed by a description of the creative process, as well as the objectives and design criteria against which the student work was analysed. We then present analysis of four design proposals produced by the students. Finally, we reflect on the overall effectiveness of the project and present some recommended strategies that can guide curriculum-integration into other programmes within higher education.

\section{CURRENT HIV AND AIDS ISSUES AND A 'NEW LITERACY OF AIDS'}

Harrison, Smith and Myer (2002, in Zisser and Francis 2006, 189) note that while previous efforts were effective in enhancing HIV and AIDS awareness, past prevention campaigns 'lacked qualities necessary to effect lasting behaviour change’. In 2003, HIV and AIDS became 
recognised as a social condition (Martin 2003, 133). Non-participatory methods to promote awareness were again noted as being ineffective in 2004 (Volks 2004, 170). Volks identified the need to actively involve people in fighting the pandemic (on both theoretical and experiential levels) and to express their responses to the pandemic, rather than simply prescribing educational programmes to raise awareness (Volks 2004, 120, 170). The current pandemic also embodies many social issues and it is clear that new social issues emerge as the pandemic continues. Current issues include denial, discrimination, stigma (Volks 2004, 170), sapped determination (Martin 2003, 127), sexual orientation, race (Mitchell and Smith 2001, 60 ), and that it only affects 'blacks', 'gays', or 'township youth', or is about 'somebody else' (Mitchell and Smith 2001, 60). Another prominent subject is that of 'AIDS fatigue' and the idea that people have become 'sick of AIDS' (Mitchell and Smith 2003, 513). This is due to an overexposure to HIV and AIDS information (Kelly 2001, in Baelden Van Audenhove and Vergnani 2012, 170). Students' frustrations with information-overload (Mitchell and Smith 2003, 514) lead them to adopt a 'dead-end attitude’. Campaigns should not promote judgement nor should they be negative by presenting death as the only outcome (Mitchell and Smith 2003, 514). To counter 'AIDS fatigue', and other social issues relating to the pandemic, there is a need for new literary narratives (Mitchell and Smith 2003, 513), and initiatives aimed at promoting HIV and AIDS awareness must be continuously, and creatively, reviewed. The development of a 'new literacy of AIDS' requires that campaigns:

- $\quad$ recognise and encourage multiliteracies, and use a variety of visual and verbal media; ${ }^{1}$

- be 'highly accessible in terms of literacy levels' (Mitchell and Smith 2003, 517) so that many people can understand the information; ${ }^{2}$

- $\quad$ use participatory strategies; ${ }^{3}$

- create messages that are unambiguous, non-cryptic, and non-abstract, and do not recklessly 'rely upon the chance understanding' (Zisser and Francis 2006, 190);

- $\quad$ encourage youth to be knowledge producers (Mitchell, Stuart, De Lange, Moletsane, Buthelezi, Larkin and Flicker 2009, 218-219; De Lange 2014, 381);

- $\quad$ use both primary and secondary prevention programmes; ${ }^{4}$

- $\quad$ carefully target specific groups, such as youth and staff on university campuses;

- develop an approach that is popular, using a target group's 'own voice' ${ }^{5}$ with contemporary forms of communication; and

- $\quad$ ensure that messages have positive rather than 'dead-end' outcomes. 
These criteria were highly influential in the development of the student project discussed later in this article.

\section{CURRICULUM-INTEGRATION, AND FADA'S RESPONSE}

As a response to the call for a 'new literacy of AIDS', curriculum-integration was identified as one approach to educating students about HIV and AIDS. Curriculum-integration is a strategic objective of the HEAIDS in South Africa. HEAIDS was established as a 'dedicated national facility to develop and support the HIV mitigation programmes at South Africa's public Higher Educational Institutions' (HEAIDS 2012, 2). The HEAIDS programme was undertaken by Higher Education SA (HESA), the representative body of South Africa's 23 public Higher Education Institutions, 'with an emphasis on building the capacity of university campuses to become key centres for mobilising whatever resources are at hand to address the pandemic' (HEAIDS 2012, 3).

The HEAIDS Policy and Strategic Framework on HIV and AIDS for Higher Education 2012-2016 is intended to guide institutions in developing their own HIV and AIDS policies and programmes (HEAIDS 2012). This policy aims to consolidate the commitment and contribution of the higher education sector towards the implementation of the 2012-2016 National Strategic Plan (NSP) for HIV, STIs and TB, and is meant to act as an institutional and sector guide, 'institutionalised through its core mission of teaching and learning, research and innovation, and community engagement' (HEAIDS 2012, 3).

In 2009, certain departments within FADA began participating in the HIV and AIDS Curriculum-Integration project, in collaboration with the University's Institutional Office for HIV and AIDS (IOHA). The IOHA serves as a partner on the UJ HIV and AIDS Committee. This office fulfils the role of coordination in accordance with the NSP for HIV and AIDS and related diseases, and functions within the legal and management framework of the UJ in accordance with the Charter of the UJ HIV and AIDS Committee (University of Johannesburg 2015, 2). The IOHA's responsibility is to steer (amongst numerous other strategies) curriculumintegration, which forms part of Objective One of the HEAIDS Policy (HEAIDS 2012, 22), to which UJ aligned its strategy regarding HIV and AIDS and related diseases. The curriculumintegration project was premised 'on the conviction that there is presently limited critical awareness of HIV and AIDS as well as human rights-related matters amongst undergraduate students generally at UJ' (University of Johannesburg 2015, 11), and equally, that 'there is a lack of focus on advocacy programmes at UJ, related to social justice issues including HIV and AIDS' (University of Johannesburg 2015, 11). Since the inception of the programme, FADA's 
participating departments have advanced the notion that 'art and design methodologies (manifesting in the form of visual campaigns) are useful approaches amongst others, to inculcate social awareness amongst the student constituencies' (University of Johannesburg 2015, 12), in order for them to make responsible choices as citizens and enable social change through education.

During the 2015-2016 cycle, this curriculum-integration project was escalated with the implementation of HEAIDS's Institutional capacity-building for the integration of HIV and AIDS into the curriculum of universities in the public education sector programme. The need for this programme arose from the fact that 'academics require capacity development in order for them to implement curriculum-integration that effectively meets the needs of employers and to prepare graduates for working in a world in which HIV and AIDS is prevalent' (HEAIDS 2014, 5). Substantial funding was awarded to FADA in the form of a Discretionary Grant Award which was made available from the National Skills Fund to support the programme.

Various other sources supported the need for capacity-building amongst academics. These sources indicate that academics need to 'make sense of HIV and AIDS for themselves' (NMEIT in Stuart 2006, 75); to have access to space and support to deal with HIV and AIDS; and to recognize their own attitudes and perspectives regarding HIV and AIDS in order to find a language with which to talk about and develop new teaching skills related to the condition (Stuart 2006, 68-75). With heightened awareness, academics (now also considered culturalproducers) have been shown to come to better understand their students' contexts and become more open and enthusiastic in their responses (Stuart 2004, 2; Stuart 2006, 68-75). Of equal importance is to ensure that graduates are sent into society 'equipped to address this pandemic on a personal, professional and intellectual basis, and to play a role in addressing HIV and AIDS in the communities in which they live, work and serve' (Volks 2004, 173).

\section{CREATIVE PEDAGOGY IN ART AND DESIGN}

The grant application for the combined 2015-2016 IOHA/FADA curriculum-integration project states that '[t]he pedagogies of art and design are intrinsically linked to culture, politics and society in general, to the human condition in particular, as well as the context in which meaning-making in art and design occurs' (University of Johannesburg 2014, 2). This has not always been the case as, historically, pedagogies of design were fundamentally linked to the material production of artefacts, creative practical skills and aesthetics. However, awareness of the unsustainability of consumer-led design has necessitated that the design industries become more socially and environmentally conscious. This has had a significant influence on formal 
design education (Campbell 2008, 84). Programmes that were primarily vocationally orientated, are now positioned in academic university environments and embrace concepts of culture, agency and social relevance (University of Johannesburg 2014, 2).

Design pedagogies and curricula are currently informed by social and behavioural sciences. Knowledge of culture, emotion, 'societal issues, techniques for subtle persuasion, and the intricacies of complex, interdependent systems' are critical if design is to be used as a means to address social and/or environmental issues (Norman and Klemmer 2014, 1). This has resulted in the concept of design as a 'problem-solving activity' becoming firmly entrenched in many pedagogical practises used in design education (Campbell 2008, 86). In order to address social problems through design, students need to develop a generalized knowledge-base and an understanding that the world is made up of complex, interrelated systems (Norman and Klemmer 2014, 2). A pedagogical approach to design teaching that aims to achieve this creates the potential for design to effect social change. These principles are being used to formulate common learning outcomes associated with project-based learning (PBL) and research within the design disciplines (Campbell 2008).

\section{Project-based learning and constructivism as pedagogical practise}

The curriculum-integration project was introduced into Interior Design 2 (an existing secondyear module). This module is structured around PBL, a common strategy used for many of the practical modules within art and design programmes. The educational principle underlying PBL is that meaning, and therefore knowledge, is derived through the making of a design or artefact. The benefit of applying PBL (Buck Institute for Education 2013) to HIV and AIDS curriculumintegration arise from the fact that PBL:

- $\quad$ requires inquiry as part of the process of learning and creating something new;

- requires critical thinking, problem solving, collaboration, and various forms of communication;

- $\quad$ is organized around an open-ended, driving question;

- $\quad$ creates a need to know essential content and skills;

- $\quad$ includes processes for revision and reflection; and

- $\quad$ involves a public audience.

Of equal significance is that PBL supports a belief system that is not didactic in nature, but rather rooted in constructivism, which is one of the main objectives of the HEAIDS programme 
(HEAIDS 2014, 14). Although it is acknowledged that 'the link between the philosophy, on one hand, and educational practice, on the other, is quite tenuous' (Murphy 1997, 3), many 'researchers, educators and authors are actively engaged in using constructivist principles to design and implement new learning environments' (Murphy 1997, 3). Here the learner interprets and constructs a reality based on their own experiences and interactions with their environment. Equally, 'concepts, models, theories, and so on are viable if they prove adequate in the contexts in which they were created' (Von Glasersfeld in Murphy 1997, 5). A constructivist approach is also preferred by Baldean et al. $(2012,174)$ who state that interactive interventions can enable students to 'discuss, define and outline their own needs' because learners are 'creative meaning-makers' (Stein and Newfield 2006 in Mitchell et al. 2009, 218). As a result, learners are valued and empowered to become producers of knowledge.

\section{SPATIAL DESIGN CONCEPTS USED IN THE STUDENT PROJECT}

Exhibition Design and Installation Art are two common spatial design concepts used to reactivate spaces. In South Africa, Exhibition Design and Interior Design are closely related. Exhibition Design is included in some curricula, alongside other fields such as retail, hospitality and corporate design. This is largely due to the fact that, unlike in some other countries, no specialist Exhibition Design courses are offered in South Africa (Museum Planner 2011). Many Interior Design graduates find employment in the Exhibition Design industry, and to a lesser extent, museums. As such, there is a need to include Exhibition Design projects in the curriculum. These can present varying degrees of complexity, depending on the level of study at which they are aimed (that is, first-, second- or third-year).

The most general application of Exhibition Design is promotion of a service or product in the form of 'exhibition-stands' created for commercial trade fairs or expositions. The most common spaces in which such stands are situated are exhibition halls and conference centres, which are highly competitive environments. The benefits of employing a designer in this case is self-evident. The designer can create a unique and novel solution for enhanced audience appeal, and in turn promote brand-awareness and differentiation from competitors. Of key educational value is that, during the design process, it is important for the designer to learn about the product or service. Other knowledge required for both Interior Design and Exhibition Design includes: materiality and construction technology; three-dimensional spatial arrangement; pedestrian traffic circulation; and, to some extent, the relatively temporary nature of certain types of interior installations.

A few principles of Installation Art were also included so as to augment Exhibition Design 
concepts. These include user-engagement and creative sensory experiences that encourage reciprocal relationships between the viewer, work, and space (Reis 1999, xiii). In combination, the use of Exhibition Design and Installation Art concepts and principles enabled unique curriculum-integration.

\section{The design process and project objectives}

Students were introduced to five HIV and AIDS themes, by an IOHA representative, in the form of a workshop. Thereafter, the students were issued a brief which stipulated the following main objectives:

- $\quad$ to promote HIV and AIDS awareness;

- $\quad$ to lead the viewer to the various IOHA locations and services; and

- $\quad$ to disseminate information.

In order to achieve these objectives, the brief also stipulated design criteria which required the students to:

- create a new, original slogan or message for the appropriate target market (staff and students) using their own popular voices;

- $\quad$ design a spatial intervention on campus, to relay this new message, and promote HIV and AIDS awareness; and

- $\quad$ use the principles of both Exhibition Design and Installation Art (especially active user participation) for their interventions.

Thereafter, the students attended a guest lecture by industry specialists in Exhibition Design, before they presented their preliminary concepts to the IOHA representative and lecturers during a studio-session at which the students received feedback. Finally, the students' final proposals were displayed at a combined FADA exhibition, with winners being identified by the IOHA.

\section{ANALYSIS OF DESIGN PROPOSALS}

Four students' proposals were analysed according to the brief's objectives and design criteria. This was done so as to determine their potential impact in contributing to a 'new literacy of AIDS'. These proposals are discussed herein based on their successful translation of the design criteria. 


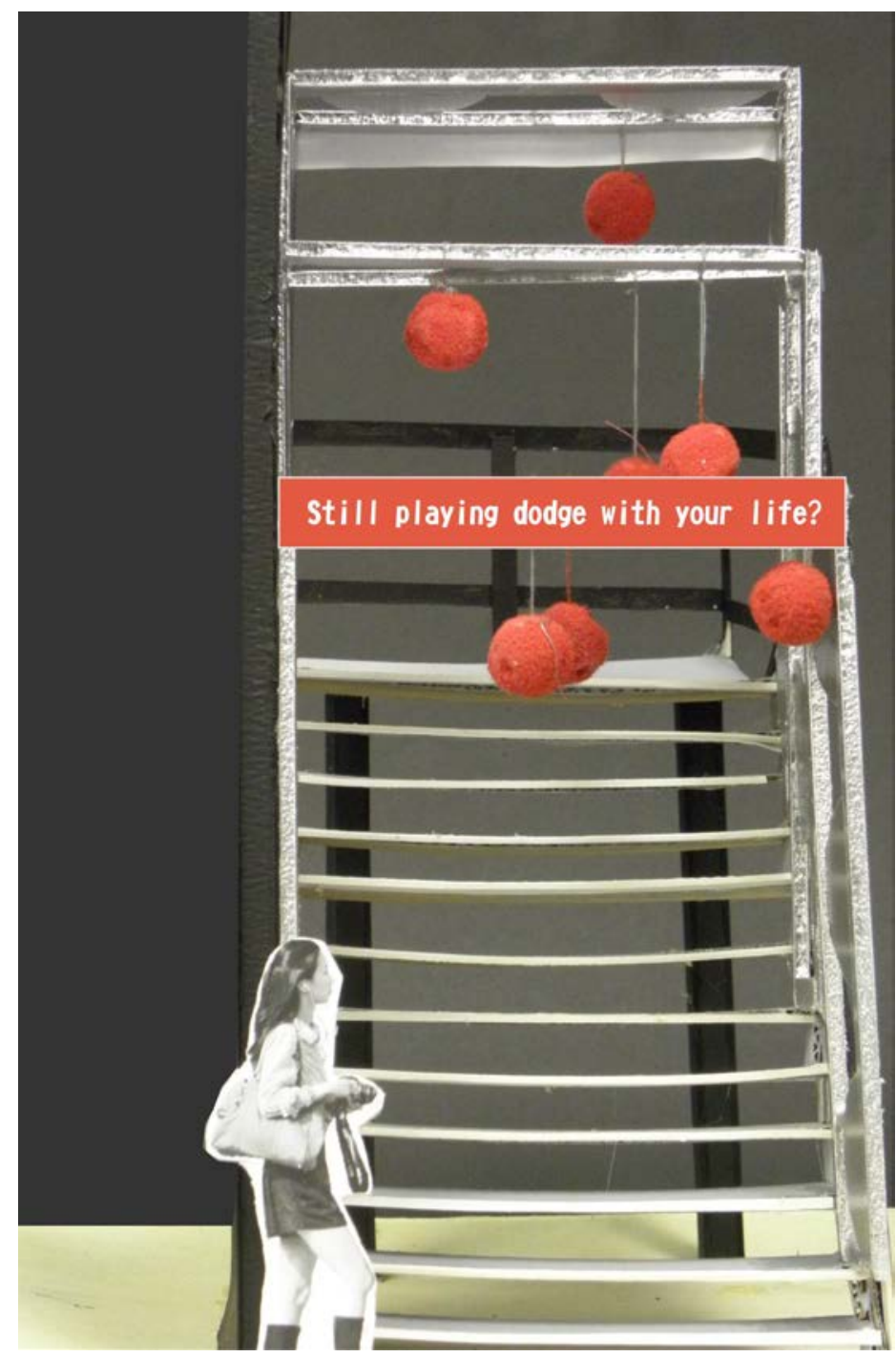

Figure 1: Still playing dodge with your life? Photograph by authors. Courtesy S. Day 2016.

The intervention depicted in Figure 1 was particularly successful with regard to the strength of its message. The proposal aimed to reactivate the FADA atrium staircase and was inspired by the sports activity, Dodgeball. The literal meaning was translated into a physical space wherein the viewer climbs up and down the staircase while being given the impression that s/he may need to physically dodge balls suspended at various points overhead. The printed slogan on a banner over the staircase, as well as the placement of the balls, makes a clear visual and literal reference to the game of Dodgeball. Dodging a ball becomes symbolic of dodging one's own responsibilities regarding sexual behaviour.

The intervention depicted in Figure 2 excelled regarding the criterion of user-engagement. The design was based upon the concept of a 'paper fortune-teller'. This is a type of origami used within a children's game, where messages are hidden inside folded flaps of paper. Messages are revealed during the game. In the proposed design, viewers must circle large-scale 


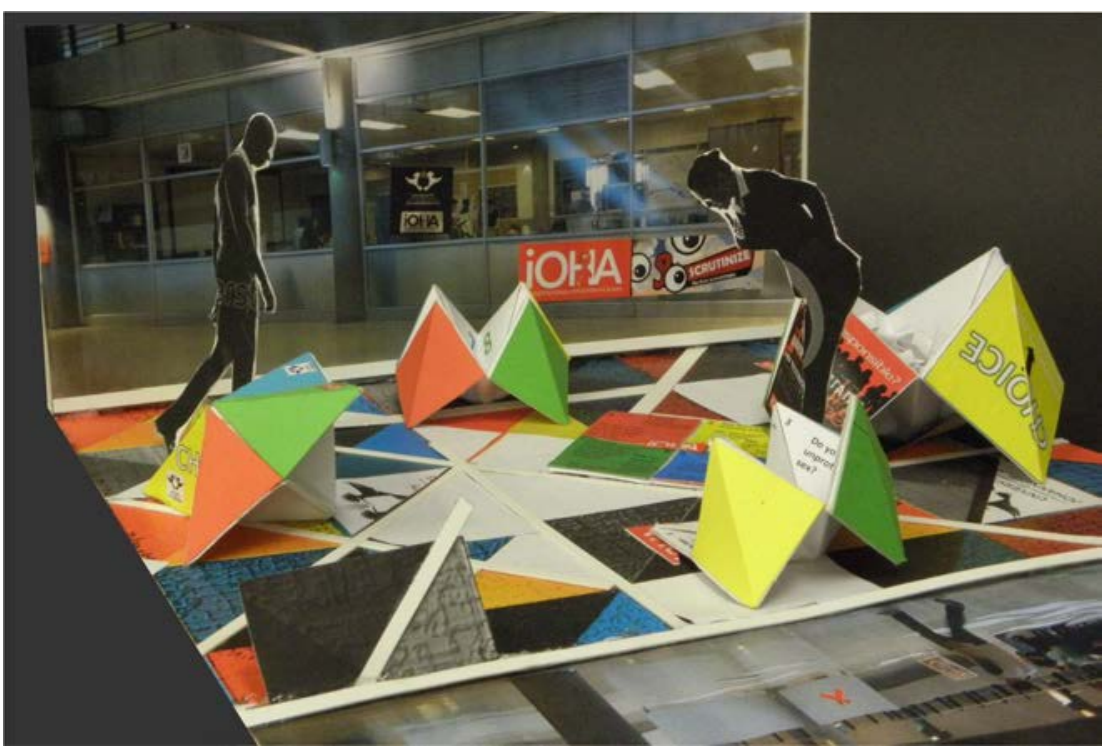

Figure 2: Choice. Photograph by authors. Courtesy F..Zulu 2016.

fortune-tellers that are marked with information. The intervention also incorporated the IOHAbranded 'paper fortune-tellers' with information, which could be taken home. The use of a variety of media to enhance user-engagement extended the installation such that viewers could play and later reflect on the topics both on-site and in their own personal space.

\section{ONE TEST IS NEVER ENOUGH}

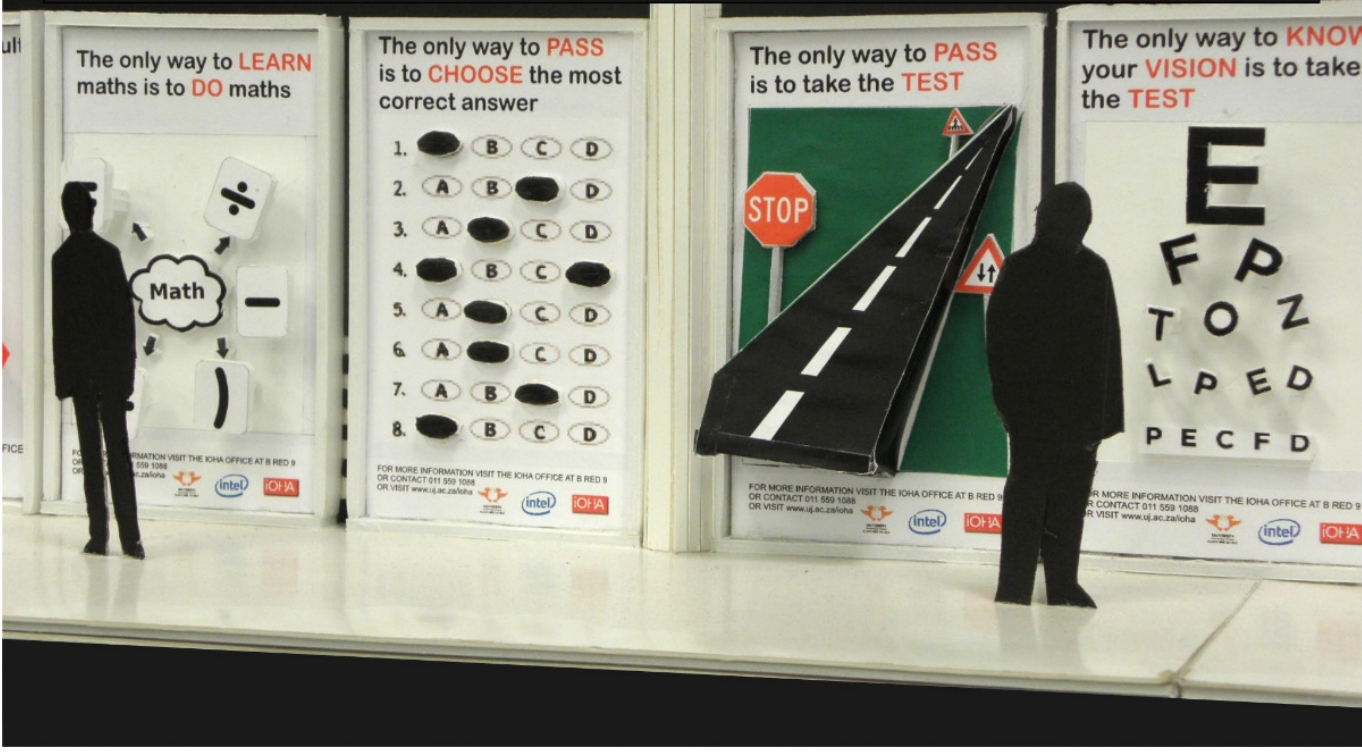

Figure 3: One test is never enough. Photograph by authors. Courtesy M. Zwane 2016.

The intervention presented in Figure 3 made successful and consistent visual reference to the 
IOHA. The design included a series of large-scale replicas of tests, with iconography associated with common, routine tests that adults regularly take. 'Getting tested' is a primary prevention strategy, and the project alerted viewers to the need to get tested regularly for HIV and AIDS, just as one might be required to take other common tests. The proposed design emphasized that the IOHA offers primary and secondary prevention programmes.

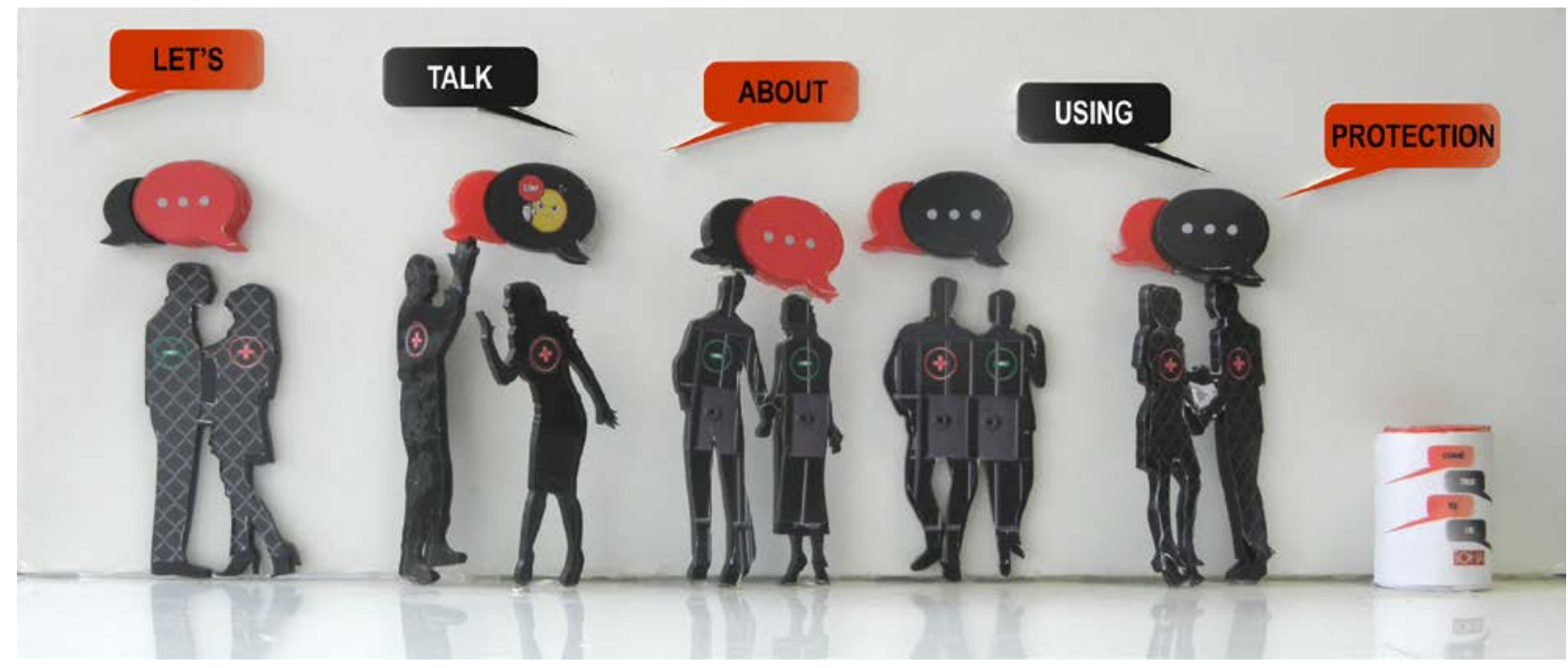

Figure 4. Let's talk about using protection. Photograph by authors. Courtesy K. Pather 2016.

Finally, the proposal illustrated in Figure 4 was rated highly based on the appropriateness of its positive, popular, and target-specific message within the design. It involved subtle placement of life-sized figures of couples talking about getting tested. This design encouraged positive, interpersonal communication as well as openness, all of which are important factors in effecting behavioural change (Baelden et al. 2012, 166; Zisser and Francis 2006, 189). The idea of openness is seen to be positive, and has no dead-end outcomes that promote fear in the form of alarming statistics or judgement of lifestyles. According to Mitchell and Smith, an underlying tone suggesting death as the sole outcome $(2003,514)$ is not ideal. This intervention uses lifesized figures that could refer to friends and couples (including same-sex couples) of no particular culture.

Analysis of the design proposals reveals that they support a 'new literacy of AIDS' through their creation of clear strong messages through a variety of media; user-engagement; heightened awareness of the IOHA and their services; and a positive approach to specific targetmarkets on campus. These proposals on the whole contribute to the promotion of HIV and AIDS awareness, as well as to the development of general interior design objectives regarding spatial arrangement and reactivation of spaces. 


\section{SUMMARY OF EFFECTIVENESS OF THE CURRICULUM-INTEGRATION PROJECT}

When evaluating the outcomes of a curriculum-integration project such as this, it is important to mention that it was undertaken within a second-year module (of a three-year diploma programme), which is an intermediate level. Although the students' proposals may not be as refined as would be expected from students at a higher level, it is beneficial to have students engage with HIV and AIDS content as early as possible. Nonetheless, the success, from a teaching and learning perspective, of using these pedagogical practises (PBL and constructivism) and curriculum-integration strategies presented numerous benefits.

- There was significant, and effective, collaboration between students, lecturers, industry experts and representatives from the IOHA within the design process. During the collaborative studio sessions, an IOHA officer guided students and facilitators towards promoting positivity and ensuring ethical content and tones.

- $\quad$ The studio became a social learning environment that enabled enhanced critical-thinking skills (see Baelden et al. 2012, 166).

- The students confidently expressed their own 'voice' and became meaning-makers in response to an authentic social problem.

- $\quad$ The students developed an understanding of the general social problem of HIV and AIDS. This contributed to their broad knowledge development which could be extended into their future professional workplace.

- The outcomes of the creative process supported a 'new literacy of AIDS'.

- Twenty-five original, and context-specific, solutions were proposed by the students (from a class of 27).

- $\quad$ The proposed interventions were generally participatory in nature; made use of a variety of media; and reflected the popular voice of the students.

- $\quad$ Representatives from the IOHA and external industry felt that many of the proposals had the potential to be built. This could be a way of extending the curriculum-integration project.

\section{CONCLUSION}

The outcomes of the curriculum-integration project generally support the idea that art-forms and spatial design concepts can be used to creatively reactivate spaces in order to communicate 
a social message. The project contributes to the 'new literacy of AIDS' through thematic arrangements in the arts, and through addressing artistic manifestations connected to the pandemic (as suggested by Tapajos 2003, 564). The project also presents an example of 'effective teaching' of HIV and AIDS, as described by De Lange (2014, 380-381), in that it is participatory, draws on experiential learning, opens up space for dialogue, is not didactic, goes beyond transfer of knowledge, and allows students to become knowledge producers. The outcomes further show that this can be effectively implemented at module level, supporting the notion that 'a variety of approaches' can be successful, which 'makes the integration process more feasible' (De Lange 2014, 376). The outcomes also serve to show that no radical curriculum change was required, which may contribute towards alleviating negative perceptions and faculty resistance to integrating HIV and AIDS issues into the curriculum. Of utmost importance, is that the project allowed the 'stories of others' to be told, and allowed students to engage in 'complicated conversations' around differing world views and differing realities so as to contribute to a deeper understanding of each other. These are all critical criteria required for effective and meaningful curriculum-integration (De Lange 2014, 381).

Although the findings of this article emerged from a project conducted in the field of art and design education, the authors feel that there are successful strategies and implications that can be considered for other programmes within higher education. The following are a list of recommended strategies for the successful integration of HIV and AIDS into existing curricula:

- to allow the principles of the 'new literacy of AIDS', as previously mentioned in the article, to guide the project briefs (where possible) in order to avoid clichéd approaches to HIV and AIDS awareness;

- $\quad$ to modify or add new concepts or themes to an existing project brief, whilst retaining the existing learning outcomes;

- to consider integrating the HIV and AIDS content as an add-on to an existing project, rather than as a stand-alone subject;

- $\quad$ to allow students to choose the HIV and AIDS sub-themes that resonate with them, with which they feel comfortable to deal with;

- to make use of subject-experts to conduct the HIV and AIDS workshops, who can later be involved in refining the students' interpretations and responses;

- $\quad$ to make use of group-projects which can further extend conversations between students;

- $\quad$ to consider trans-disciplinary collaboration with creative disciplines; and

- $\quad$ to employ curriculum-integration at earlier levels in an undergraduate programme where outputs can be more conceptual. 


\section{NOTES}

1. New media may include interactive communication platforms like chat rooms, artistic forms, and social media (Mitchell et al. 2009, 218; Mitchell and Smith 2003; Baelden et al. 2012, 169).

2. When using a variety of media and alternative literary forms (narratives using photographs and voice bubbles), messages must be widely and easily understood (Stuart 2004,1; Mitchell and Smith 2003, 517).

3. Examples of participatory strategies are workshops with experiential and expressive components that incorporate drama, art and narrative therapy (Volks 2004, 172).

4. Efforts to stop the spread of the virus in the past 20 years are divided into primary prevention programmes aiming to prevent new HIV infections, and secondary prevention programmes aiming to treat existing HIV infections. (Benotsch et al. in Baelden et al. 2012, 167).

5. In 2006, there was a need to aim interventions at high-risk populations, and to promote culturally relevant messages (Harrison et al. in Zisser and Francis 2006, 189) that are popular, and culturally and geographically relevant (Mitchell et al. 2009, 215; loveLife 2004 in Francis and Rimensberger 2005, 88; Ford et al. 2003 in Mitchell et al. 2009, 218).

\section{REFERENCES}

Baelden D., L. Van Audenhove and T. Vergnani. 2012. Using new technologies for stimulating interpersonal communication on HIV and AIDS. Telematics and Informatics (29): 166-176.

Buck Institute for Education. 2013. What is project based learning (PBL)? http://bie.org/about/what_pbl (accessed 7 March 2013).

Campbell, A. D. 2008. Industrial Design Education and South African imperatives. Image \& Text: A Journal for Design 14: 89-99.

De Lange, N. 2014. The HIV and AIDS academic curriculum in higher education. South African Journal of Higher Education 28(2): 368-385

Francis, D. and N. Rimensberger. 2005. Selling HIV/AIDS prevention: A case of mixed messages. Acta Academia 37(3): 86-105.

Gobind, J. and W. Ukpere. 2012. Accessing HIV awareness and prevention information: South African challenges. African Journal of Business Management 6(50): 11999-12004.

Gobind, J. and W. Ukpere. 2014. Evaluating HIV/AIDS Programme within South African universities. Mediterranean Journal of Social Sciences 5(3): 346-357.

Grierson, E. and L. Brearley. 2009. Ways of framing. In Creative arts research: Narratives of methodologies and practices, ed. E. Grierson and L. Brearley. Rotterdam: Sense Publishers.

HEAIDS see Higher Education HIV and AIDS Programme.

Higher Education HIV and AIDS Programme. 2012. Policy and Strategic Framework on HIV and AIDS for Higher Education. Pretoria: HEAIDS.

Higher Education HIV and AIDS Programme. 2014. Institutional capacity-building for the integration of HIV and AIDS into the curriculum of universities in the public education sector. Pretoria: HESA.

Martin, M. 2003. HIV/AIDS in South Africa: Can the visual arts make a difference? In AIDS and South Africa: The social expression of a pandemic, ed. K. D. Kauffman and D. L Lindauer, 120-135. New York: Palgrave Macmillan.

Mitchell, C. and A. Smith. 2001. Changing the picture: Youth gender and HIV/AIDS. Canadian Woman Studies 21(2): 56-61.

Mitchell, C. and A. Smith. 2003. 'Sick of AIDS': Life, literacy and South African youth. Culture, Health \& Sexuality 5(6): 513-522. 
Mitchell, C., J. Stuart, N. de Lange, R. Moletsane, T. Buthelezi, J. Larkin and S. Flicker. 2009. What difference does this make? Studying youth as knowledge producers within a new literacy of HIV and AIDS. In Critical language and literacy studies: Language and HIV/AIDS, ed. C. Higgins and B. Norton, 214-232. Clevedon: Multilingual Matters.

Murphy, E. 1997. Constructivism: From philosophy to practice. files.eric.ed.gov/fulltext/ED444966.pdf (accessed 20 August 2013).

Museum Planner. 2011. Getting started in museums. http://museumplanner.org/getting-started-inmuseums/ (accessed 12 October 2015).

Norman, D. and S. Klemmer. 2014. State of design: How design education must change. http://www. jnd.org/dn.mss/state_of_design_how.html (accessed 15 February 2015).

Reis, J. H. 1999. From margin to center: The spaces of installation art. Cambridge: The MIT Press.

Shefer, T., A. Strebel and J. Jacobs. 2012. AIDS fatigue and university students' talk about HIV risk. African Journal of AIDS Research 11(2): 113-121.

Stuart, J. 2004. Media matters: Producing a culture of compassion in the age of AIDS. English Quarterly 36(2): 3-5.

Stuart, J. 2006. 'From our frames': Exploring with teachers the pedagogic possibilities of a visual arts based approach to HIV and AIDS. Journal of Education (38): 67-87.

Tapajos, R. 2003. HIV/AIDS in the visual arts: Applying discipline-based art education (DBAE) to medical humanities. Medical Education (37): 563-570.

University of Johannesburg. 2014. Faculty of Art, Design \& Architecture. Annexure A. National skills funding application form. Johannesburg.

University of Johannesburg. 2015. Sustained excellence: Health and wellness. HIV/AIDS committee annual report 2015. Johannesburg.

Volks, C. 2004. The role of tertiary institutions in the HIV/AIDS epidemic. In AIDS and South Africa: The social expression of a pandemic, ed. K. D. Kauffman and D. L. Lindauer, 161-175. Hampshire: Palgrave Macmillan.

Wood, L. 2011. Faculty views of HIV and AIDS education in the curriculum at tertiary level. South African Journal of Higher Education 25(4): 819-837.

Zisser, A. and D. Francis. 2006. Youth have a new attitude on AIDS, but are they talking about it? African Journal of AIDS Research 5(2): 189-196. 